\title{
Carácter autobiográfico de la Carta 132 de S. Agustín
}

\author{
La carta 132 la dirige Agustín a Volusiano. El personaje no nos resulta \\ desconocido ${ }^{1}$. Con toda probabilidad Agustín ya había mantenido contacto \\ personal con él. El mismo tono de la carta no es el único indicio ${ }^{2}$. Sea como
}

1. Rufio Antonio Agripnio Volusiano era un romano que, probablemente buscando la paz y la seguridad ante la inestabilidad política de Italia que condujo al saqueo de Roma por parte de Alarico en agosto del 410, se había afincado en Cartago. Allí había ejercido el cargo de procónsul en fecha aún desconocida con exactitud, pero ciertamente antes del 411 . Perteneció a la familia noble de los Ceionios. Su nacimiento debió ocurrir hacia el 382.

"No sabemos a título de qué se hallaba entonces Volusiano en Cartago; sin duda era a título privado, habiendo huido, como tantos otros romanos ricos y de alto rango, de Roma y de la confusión que acompañó a la toma de la villa por Alarico en 410 . Todo parece indicar que entonces no estaba allí ejerciendo una función pública, sino reclamado más bien por la administración de sus bienes. Su abuelo C. Caeionius Rufius Volusianus se halla mencionado en una inscripción de Tubursicu Bure como propietario de un gran dominio y la importante familia de los Ceionios figura en el número de las familias de lá aristocracia romana que poseían vastos latifundios en Africa. En todo caso Volusiano no parece estar ocioso, pues Agustín habla de sus «ocupaciones diversas»" (M. MOREAU, Le dossier Marcellinus dans la correspondance de saint Augustin, en Recherches Augustiniennes 9, p. 53). Cf. A. CHASTAGNOL, Le sénateur Volusien et la conversion d'une famille de l'aristocratie au Bas-Empire, en Revue des Études Anciennes 58 (1956) 241-253; ID. Rufius Antonius Agrypnius Volusianus, en Les Fastes de la préfecture de Rome au Bas-Empire. Études prosopographiques II, Paris 1962, 276-279.

2. Así se puede deducir del hecho concreto de que al final de la carta 137 Agustín le envíe saludos de parte de Posidio, y lo permite intuir el cargo de procónsul que ocupó con anterioridad a la carta, siendo ya obispo Agustin. Igualmente el modo como comienza la carta parece indicar que el diálogo entre Agustín y Volusiano venía de atrás y que no hacía sino continuar, quizá a un nivel distinto. Así se expresa M. Moreau: “... la carta sugiere relaciones estrechas entre Agustín y su corresponsal. Tal vez ellos se han encontrado recientemente, durante la breve estancia de Agustín en Cartago con ocasión de la Conferencia; tal vez se conocían ya desde antiguo, desde el año en que Volusiano debió ser procónsul en Africa" (o. cit., p. 52-53). 
sea él se mantenía en relación estrecha con familiares muy cercanos ${ }^{3}$. Cabe la probabilidad de que la misma madre de Volusiano haya intercedido ante Agustín para que escribiera esta carta. No existen pruebas textuales, pero podemos deducirlo del comienzo de la carta, en que Agustín compara su deseo de la salud espiritual de Volusiano al de la madre de éste, y de la insistencia de ella ante Marcelino para que le visite con frecuencia ${ }^{4}$. Cabe suponer que haya repetido ese mismo proceder con Agustín.

Volusiano aún no se había liberado del paganismo, pero en su entorno familiar la fe cristiana se hacía valer, incluso en formas un tanto radicales ${ }^{5}$. Él mismo se encontraba ya cerca de ella, siguiendo lo que había pasado a ser, aunque con numerosas excepciones, la norma de la nobleza romana. $\mathrm{Su}$ amigo el tribuno Marcelino, al reclamar de Agustín la respuesta a las dificultades que él le plantea, habla de "los pasos un tanto vacilantes de este hombre" 6. Algunas de estas dificultades que impedían a muchos dar el salto definitivo las conocemos por la contestación de Volusiano (carta 135) y otras por la que le escribe a Agustín el mencionado Marcelino (carta 136). En efecto, la carta 132 es la primera de un corpus de cinco, todas ellas con Volusiano como personaje central; tres tienen como autor a Agustín (cartas 132, 137 y 138), una al mismo Volusiano (carta 135) y otra a Marcelino (carta 136) y como destinatarios a Volusiano (cartas 132,137), a Agustín (carta 135, 136) y a Marcelino (carta 138).

Es útil hacer todavía otra aclaración. Aunque la carta 132 tiene un marcado carácter personal, en las demás Volusiano se convierte ya en cierto modo en un personaje colectivo, incluyendo al grupo de amigos con quienes suele reunirse de forma periódica en una especie de círculo filosófico-litera-

3. En concreto con su hermana Albina, mujer de Panmaquio, hijo de Melania la Mayor.

4. Ep. 136,1: ... sanctae si quidem matris eius precatione compulsus cura mihi est eum frecuentius salutandi.

5. Su padre, Rufio Albino era aún pagano, pero su madre, cuyo nombre no nos ha llegado, era ferviente cristiana. En el cierre de su segunda carta a Volusiano Agustín saluda sanctam et in Christo dignissime honorandam matrem, cuius pro te preces Deus exaudiat (ep. 137,5,20). Su hermana Albina fue también ardiente proselitista de la fe cristiana.

6. Ep. 136,1: ... quod hominis gressus aliquanto titubantes boni propositi exhortatione statuere et firmare contendis. En la carta que escribe a Agustín se refiere a uno que preguntó si había alguien informado del cristianismo qui ambigua, in quibus haereo, possit aperire dubiosque adsensus meos vera vel verisimile credulitate firmare (ep. 135,2). Estos dubios adsensus traen a la memoria aquella ancipitem fluctuationem con que describe Agustín su situación al inicio del libro sexto de las Confesiones (6,1,1). Así comenta M. Moreau: "Mas por el momento Volusiano está clavado, paralizado en la duda (ambigua in quibus haereo): deseo angustiado de catecúmeno, y rechazo de intelectual" (o. cit., p. 56). 
rio 7. Los problemas planteados no son específicos de la persona concreta, Volusiano en este caso, sino de todo el grupo y, ampliando más el radio, de una categoría de hombres, ciertos intelectuales aún no convertidos. Igualmente, la respuesta de Agustín mira a todo el grupo y no sólo al destinatario nominal de la carta. Ese era el deseo expresado por Marcelino: "Mas, por eso mismo, puesto que confío en que lo que tú escribas va a ser de gran provecho para muchos, me sumo a su (de Volusiano) ruego, para que te dignes contestar con especial atención a esas mentiras que propalan" 8. Lo mismo repite al concluir su carta: "Hay que ofrecer una solución plena, clara y bien pensada a todos los problemas, puesto que sin duda correrá por muchas manos la respuesta que se desea de tu santidad... Yo, a todo esto... reclamo tu promesa: te pido que escribas algunos libros que han de aprovechar increíblemente a la Iglesia especialmente en estos tiempos" 9 .

Volusiano era un hombre cultivado. Refiriéndose a él, escribe Marcelino a Agustín: "En un estilo, como tú mismo puedes comprobar, culto y atildado, con toda la brillantez de la elocuencia romana te pide que le resuelvas algunas cuestiones" 10. Hasta tal punto era esclavo de la preceptiva literaria clásica que renuncia a presentar a Agustín todas sus dificultades respecto a la fe cristiana por no quebrantarla 11. Era lógico, pues, que Agustín, hombre de letras que se dirige a un hombre también cultivado y que en el momento apreciaba más que él esos valores, le escribiera respetando escrupulosamente esa misma preceptiva. En efecto, la carta con que se introduce es breve, ateniéndose a lo que exigían los cánones del género epistolar. A la afirma-

7. Los componentes de este grupo los describe M. Moreau de la siguiente manera: "¿Quiénes eran los que allí se reunían? Sin duda altos funcionarios en ejercicio en la provincia, notables, propietarios de grandes posesiones. Volusiano es lo uno y lo otro, y la carta 136 señala la presencia de un rico propietario de la región de Hipona llegado sin duda a Cartago para tramitar algún asunto, o por motivos de diversión. Bastantes de entre ellos son emigrados que ante los disturbios que se abatían sobre Italia han venido a buscar a Africa, donde algunos de ellos como Volusiano tienen posesiones, la seguridad de una vida más tranquila, y una continuidad romana amenazada en todas partes" (o. cit., p.124). Por lo que al aspecto intelectual se refiere, así lo define la misma autora: "Existe la tentación de ver en el grupo reunido en torno a Volusiano no un círculo de filósofos, ni tampoco los posesores retrasados de una cultura clásica ya perecida, sino un grupo intelectualmente bien vivo, alimentado con una de las corrientes más "actuales" entonces del pensamiento pagano, el neoplatonismo porfiriano, que, situado en las fronteras de la actitud filosófica y de la actitud religiosa, era deliberadamente hostil al cristianismo" (p. 127).

8. Ep. 136,1.

9. Ep. 136,3 .

10. Ep. 136,1.

11. Ep. 136,2: Ipse autem vir illustris... multas esse dixit praesentibus aliquantis, quae huic possint iungi non inmerito, quaestiones, sicut ante dixi, si non ab eius partibus epistularis considerata brevitas fuisset. 
ción no le quita validez el hecho más que probable de que no la conservemos en su integridad. El comienzo ciertamente parece un tanto atípico y el final algo brusco y poco cortés para un texto rebosante de cordialidad y familiaridad, hasta hacer pensar que carece de la conclusión. Hablamos únicamente del comienzo y de la conclusión y no de algo más, porque la respuesta de Volusiano no hace referencia a otra cosa que no hallemos en el texto conservado 12 .

Antes avanzamos la hipótesis de que haya sido la madre de Volusiano quien invitó a Agustín a intervenir ante su hijo para llevarle definitivamente a la fe cristiana. Adujimos razones que a nuestro modo de ver la hacen probable; ahora añadimos una más, que no es otra que lo que pretendemos mostrar en estas páginas, a saber: Agustín se encuentra con la difícil tarea de conducir a la fe cristiana a este hombre. Antes de dirigirse a él piensa en el camino de más fácil recorrido para alcanzar esa meta, en las dificultades que presumiblemente encontrará y en la forma de solucionarlas. Sus reflexiones no van a tomar un carácter puramente teórico y abstracto; antes bien, las va a personalizar. Piensa que el caso de Volusiano puede ser un doble del suyo en el periodo anterior a la conversión, pues ambos coinciden en puntos muy importantes; a ambos les une el estar imbuidos de amor a la cultura clásica, y el estar, resp. haber estado, en un camino a cuya meta no acaba/acababa de llegar. Agustín repasa su experiencia: qué fue definitivo en el hecho de que él personalmente diese ese paso; cuáles fueron las dificultades que hubo de superar, qué ayudas recibió y qué equivocaciones tuvo que lamentar. Agustín considera a Volusiano como un nuevo Agustín, y quiere presentarse frente a él como el nuevo Ambrosio. La acción de Ambrosio sobre sí mismo en su etapa milanesa, que fue tan decisiva ya directa ya indirectamente, quiere repetirla él sobre el nuevo Agustín, ahora llamado Volusiano. Es lo que pretendemos probar en las páginas que siguen.

Volviendo a la hipótesis que antes avanzamos la concretamos de esta manera. La madre de Volusiano, conocedora de Agustín y ¿por qué no? de

12. Aunque la objección podría venir de la carta de Marcelino que comienza ponderando al máximo la primera de Agustín a Volusiano, hasta el punto de forzar a éste a que la lea a muchos, y expresando la admiración por lo que dice (ep. 136,1). Pero se puede entender perfectamente, creemos, de la actitud de Agustín a responder a cuantas dificultades se puedan presentar en la lectura de la Escritura.

13 Sabemos que circulaban en Roma como lo prueba el hecho narrado por Agustín en De dono perseverantiae 20,53 con Pelagio como protagonista; en Roma debió leerlas también el maniqueo Secundino (P. CourCElle, Recherches sur les Confessions de saint Augustin, Paris 1950, 236-238; 245-247). 
sus Confesiones ${ }^{13}$, quiere convertirse en la nueva Mónica; y como ésta recurría a todos los obispos intentando que ellos hablasen con su hijo maniqueo para que lo recondujesen a la fe católica, así ella recurre ahora a todos los mediadores a los que tiene acceso. Nos consta positivamente de su insistencia ante Marcelino ${ }^{14}$. Cae dentro de lo posible que haya recurrido a Agustín también. Así se explicarían los datos que el santo obispo aporta sobre ella al inicio de la carta 132 y en la conclusión de la 137 15. Es este uno de los diversos puntos que, a nuestro entender, permiten ver que Agustín, al dirigirse a Volusiano, trabaja con el recuerdo de su historia personal, a la hora de orientarle con vistas a que se decidiera a abrazar la fe cristiana. Los puntos aludidos se concretan en estos rótulos:

a) La madre de Volusiano

b) Invitación a la lectura de la Escritura

c) Valoración de la Escritura

d) Orden de lectura

e) Contacto epistolar

Para comprender la carta, que es en definitiva nuestro objetivo, estableceremos una comparación con las Confesiones, conforme al siguiente método: primero presentamos el texto de la misma que se refiere al punto tratado; luego lo seguimos en las Confesiones para verlo realizado en la vida de Agustín; por último, intentamos captar el sentido de la aplicación a Volusiano. Veamos cada uno de los puntos por separado.

\section{a). La madre de Volusiano}

En el comienzo de la carta Agustín hace alusión a la madre de Volusiano recordando la coincidencia mutua en los deseos respecto a Volusiano: "En un punto quizá pueda yo igualarme a tu santa madre: en los deseos por la salud que anhelo tengas en este mundo y en Cristo" 16.

14. Cf. nota 4 .

15. Cf. nota 5 y 16. Esta es la opinión, una vez más, de M. Moreau: "Tal vez Agustín se ha decidido a escribirle a petición de su madre, que deseaba verle cristiano; la carta en efecto, comienza por estas palabras: 'En un punto quizá pueda yo igualarme a tu santa madre: en los deseos por la salud que anhelo tengas en este mundo y en Cristo'. Esta reflexión invita a suponer, o que Agustín ha recibido una carta de la madre de Volusiano... o que le ha llegado un mensaje de ella, tal vez por mediación de Albina y de Melania, hermana y sobrina de Volusiano, que acababan de llegar a Africa con Piniano, esposo de Melania, que son cristianos ardientes y que se hallan en relación estrecha con Agustín (ep. 124)" (o. cit., p. 52-53).

16. De salute tua, quam et in hoc saeculo et in Christo esse cupio, sanctae matris tuae votis sum fortasse etiam ipse non impar. Dada la brevedad de la carta, no consideramos necesario indicar las referencias a la misma. 
Un mínimo conocimiento de las Confesiones lleva a pensar de inmediato en Mónica, la madre de Agustín. Tal como el mismo Agustín nos la presenta, ella está obsesionada por esa salud de su hijo, salud tanto física como sobre todo espiritual. Y es a sus oraciones a las que atribuye haberla recuperado cuando la había perdido. Respecto a la enfermedad contraída en Roma, escribe así: "Mi madre no estaba enterada de mi postración, pero oraba en mi ausencia por mí. Y tú que estabas continuamente presente donde ella estaba, la oías a ella. Y donde estaba yo, tenías piedad de mí para que recobrase mi salud corporal, manteniéndose todavía la enfermedad de mi impío corazón" 17.

Un poco después hace ya mención de la salud espiritual: “¿Ibas a despreciar las lágrimas con que ella te pedía no oro ni plata, ni bienes mudables o volubles, sino la salud del alma de su hijo? ¿Ibas a desairar y a negar tu ayuda a aquella mujer que, por don tuyo, era lo que era? De ninguna manera, Señor, sino todo lo contrario. Tú la apoyabas y la escuchabas, secundando sus peticiones según el orden que tenías predestinado para tu actuación" ${ }^{18}$. Y todavía un poco después menciona juntas las dos clases de salud: "Hiciste, pues, que convaleciera de aquella enfermedad y diste la salud al hijo de tu sierva. Por entonces te limitaste a restablecerme corporalmente, esperando la oportunidad de regalarme una salud mejor y más segura" 19. Mónica entonces actuaba desde lejos únicamente con su oración.

Estos textos se refieren al período romano de Agustín; pero la misma presentación encontramos en su época milanesa con Mónica ya presente. "Amaba a aquel hombre (Ambrosio) como a un ángel de Dios desde el momento en que supo que por conducto de él yo había llegado a aquella situación interina de perpleja ambigüedad, que iba a ser como un estadio transitorio entre la enfermedad y la salud, una vez superado el momento de más peligro, algo así como ese acceso que los médicos califican de crítico" ${ }^{20}$. Y casi a continuación: "Mi madre le amaba cordialmente por su influencia en mi salud, y él la apreciaba a ella por su buen talante, por la vida piadosísima con que asistía asiduamente a la Iglesia y por el gran fervor espiritual de las buenas obras" 21 .

La novedad de estos últimos textos consiste en la introducción de Ambrosio como nuevo agente de la salud de Agustín. Un Ambrosio de

17. Confessiones $5,9,16$.

18. Conf. 5,9,17.

19. Conf. 5,10,18.

20. Conf. $6,1,1$.

21. Conf. 6,2,2. 
quien él mismo dirá que enseñaba una reconfortante lección de salud ${ }^{22}$. De esta manera, cada uno a su modo, Mónica y Ambrosio, actuaban en la misma dirección y tendían al mismo objetivo. Con una diferencia: que, salvo encuentros ocasionales, no consta en los textos la relación directa y personal de Ambrosio con Agustín. Este se beneficia, como uno más entre tantos otros, de la labor curativa del obispo, que, al decir de Agustín, ignoraba su situación. "Siempre que Ambrosio me veía, prorrumpía en alabanzas suyas (de Mónica), felicitándome por tener una madre como ella. Se ve que desconocía qué clase de hijo era yo: un escéptico que dudaba de la eficacia de todas aquellas buenas obras y que estaba convencido de la imposibilidad de hallar el camino de la vida" 23 . Con todo, queda en pie la acción conjunta de madre y obispo con vistas a la salud espiritual de Agustín.

La carta 132 comienza justamente mostrando esa conjunción de deseos entre la madre y el obispo. Si grande es el de la madre, no es menor el de Agustín: "En un punto quizá pueda yo igualarme a tu santa madre: en los deseos por la salud que anhelo tengas en este mundo y en Cristo". Obviamente aquí aún nos hallamos a nivel de deseo. Deseo que justifica la acción emprendida. Cual nuevo Agustín, Volusiano cuenta también con la acción conjunta de su madre y de un nuevo Ambrosio, esta vez. Agustín 24.

Cabe pensar que, recibida la invitación de la madre de Volusiano, a Agustín le vino a la memoria el recuerdo de la suya que le hizo revivir su experiencia y a partir de ahí tejió las líneas de su carta.

\section{b) Invitación a leer la Escritura}

La autenticidad de un deseo se traduce en la puesta en acción de los medios para hacerlo realidad. Agustín, anhelante de la salud en Cristo de Volusiano, le recomienda la lectura de las Escrituras. "Te exhorto con todas mis fuerzas a que no te duela entregarte de lleno a las Letras verdadera y ciertamente santas" 25 .

La exhortación tiene su fundamento en Agustín en el principio puesto por él de que la Escritura es como el botiquín en el que el Señor ha puesto todos los medicamentos que requiere la salud del hombre ${ }^{26}$. Pero lo tiene

22. Conf. $5,13,23$

23. Conf. 6,2,2.

24. Con la diferencia de que en el caso de Agustín Ambrosio no tomó una parte tan conscientemente activa como la está tomando ahora Agustín respecto a Volusiano.

25. ... hortor, ut valeo, ut litterarum vere certeque sanctarum te curam non pigeat inpendere. 26. Sermo 32,1. 
sobre todo en su experiencia personal. No es preciso detenernos en el papel que han jugado las Escrituras cristianas en su camino hasta la fe plena y católica ${ }^{27}$.

La Escritura está presente en el primer momento intenso del despertar religioso de Agustín, tras la lectura del Hortensio ${ }^{28}$. No importa al respecto que en aquel momento su efecto fuese de inmediato negativo desde el punto de vista católico, puesto que ahí se asentaron las bases para el positivo posterior. En todo caso no se puede negar su influjo en la vivencia religiosa dentro del maniqueísmo.

De otro signo, netamente positivo esta vez, es el influjo de su encuentro con la Escritura en su etapa milanesa. Un primer encuentro que podemos considerar como pasivo tuvo lugar oyendo la predicación de Ambrosio. El obispo consiguió derribar las barreras que le impedían acercarse a la Escritura católica, es decir, en la plenitud e integridad del Antiguo y Nuevo Testamento. "Es cierto que le oía todos los domingos predicar al pueblo rectamente la palabra de la verdad, y que al mismo tiempo iba aumentando mi convicción personal de que tenían posibilidad de solución todas las dificultades que las maliciosas interpretaciones de aquellos embaucadores míos (maniqueos) achacaban a los libros divinos" ${ }^{29}$. De esta manera el abrírsele la posibilidad de acceso a la Escritura significó al mismo tiempo la posibilidad de retorno a la fe católica.

De signo igualmente positivo, pero de carácter ahora activo, es el encuentro con la Escritura en las fechas anteriores a la escena del huerto y en ella misma ${ }^{30}$. La decisión definitiva de convertirse en siervo de Dios fue estimulada por la lectura de un texto de San Pablo en su carta a los Romanos $(13,13-14)$.

Pero como más importante incluso que éste, aunque no tan celebrado, hay que considerar el encuentro previo con ella, posterior a la lectura de los libros de los neoplatónicos: “Así, pues, con toda avidez, cogí las Escrituras venerables de tu Espíritu, con preferencia el apóstol Pablo, y fueron desvaneciéndose todos aquellos problemas en que a veces me parecía descubrir contradicciones e incoherencias entre sus palabras y el testimonio de la Ley y los profetas" ${ }^{31}$. La importancia de este encuentro en aquel momento preci-

27. Cf. B. DE MARgerie, Introduction à l'histoire de l'exégèse. III. Saint Augustin. Paris 1983, p. 18-25; A. M. LA BonNARdIERE, L'initiation biblique d'Augustin, en Saint Augustin et la Bible, Paris 1986, p. 27-47.

28. Conf. $3,5,8$.

29. Conf. 6,3,4.

30. Conf. $8,6,14 ; 8,12,30$.

31. Conf. 7,21,27. 
so no la hemos de ponderar nosotros porque el mismo Agustín se encarga de hacerlo con estas palabras: "Si hubiera comenzado por instruirme en tus sagradas Letras, saboreando tus dulzuras una vez familiarizado con ellas, y a continuación hubieran caído en mis manos aquellos libros, tal vez me habrían erradicado de las bases sólidas de la piedad. Incluso, en caso de persistir en los sentimientos saludables que había asimilado, pensaría en la posibilidad de que también en estos libros se pueden agenciar tales sentimientos, siempre que uno se limite al estudio de estos libros nada más" ${ }^{32}$. Con otras palabras, el encuentro con la Escritura significó para Agustín el emprender el camino abierto a la meta buscada, y la exclusión de otro que, aunque le mostrase la meta, no le indicaba cómo llegar a ella. Nada mejor que recoger una vez más sus palabras: "Inicié su lectura, y descubrí que cuanto de verdadero había leído allí (en los libros neoplatónicos), también se decía aquí (en la Escritura), pero con la garantía de tu gracia, para que el que ve no se gloríe como si no hubiera recibido no sólo lo que ve, sino hasta la facultad de ver... De este modo se le intima al hombre no sólo a verte a ti que eres siempre el mismo, sino también se le intima a que sane y te posea. Y aquel que se halla lejos de ti y no puede verte, que ande por este camino que le permitirá llegar, ver y poseer" ${ }^{33}$.

En definitiva, Agustín difícilmente sabría dar explicación de su vuelta a Dios dejando de lado la Escritura. Si ella contribuyó a que fuese a caer en el maniqueísmo, ella misma le sacó de la trampa no menos peligrosa que significaba la filosofía neoplatónica, peligrosa entre otras razones por su tinte religioso, hasta el punto de constituirse en alternativa a la religión pura y simple. Es lógico, pues, que tratando de orientar a Volusiano le recomendase su lectura.

No sabemos con exactitud hasta qué nivel Agustín conocía a Volusiano, la extensión de su cultura, de sus intereses, o de dónde le llegaban las dificultades para abrazar la fe cristiana. Pensar en la filosofía no resultaba extravagante. Aunque la retórica ocupaba el trono del saber, en ningún modo excluía la misma filosofía, como había acontecido en su caso. La filosofía neoplatónica había irruído con fuerza en su vida, y no por puro accidente, sino porque era la que dominaba el ambiente cultural. Sus aspectos positivos eran innegables, igual que los negativos, que él pudo superar gracias a la lectura subsiguiente de la Escritura. Cabía imaginar que Volusiano se hallase en idénticas dificultades.

32. Conf. 7,20,26.

33. Conf. $7,21,27$. 
La carta de Volusiano nos informa sobre los temas de discusión en los cenáculos culturales de que él formaba parte. Allí se discutía de retórica, de poesía y de filosofía ${ }^{34}$. Por lo que se refiere a ésta última, curiosamente hay una divergencia entre lo que se discute y lo que se vive. Las discusiones de filosofía parece que se planteaban a nivel histórico y se preguntaban "qué había aportado el preceptor del Liceo, qué la duda múltiple y continuada de la Academia, qué aquel dialéctico del Pórtico, qué la ciencia de los físicos, qué el placer de los epicúreos, qué finalmente el infinito afán de discutir entre todos y el hecho de que la verdad es más ignorada después de haber presupuesto que puede ser conocida" 35 . No se hace mención aquí de la filosofía neoplatónica, y sin embargo, las dificultades concretas que se plantean a la fe cristiana: imposibilidad de la encarnación, insignificancia de los milagros, proceden de ese ámbito cultural ${ }^{36}$.

Ante este fondo neoplatónico, conocido o sólo intuido en Volusiano, de donde procedía el último obstáculo que Agustín tuvo que superar, se comprende que éste le haya dado la receta que le curó a él: la lectura de la Escritura.

\section{c) Valoración de la Escritura}

Agustín no se limita a recomendarle vivamente que lea la Escritura. En su carta añade unas consideraciones que no carecen de importancia. "Es una realidad auténtica y sólida; no fascina al alma con palabras rebuscadas ni susurra algo vano y tornadizo bajo los celajes de la lengua. Impresiona mucho al que está ávido de realidades y no de palabras y mucho aterra, mas para darte seguridad" 37.

34. Ep. $135,1$.

35. $I b$.

36. "Sin duda alguna el dogma de la Encarnación puede repugnar a un espíritu simplemente racional. Pero el problema de la unión del alma y del cuerpo que está en el centro de la objección presentada aquí, es central en el pensamiento de Porfirio que lo resuelve de forma incompatible con la interpretación cristiana, puesto que rechaza absolutamente todo lo corporal para no perseguir más que la salud del alma. Y como lo ha mostrado E.L. Fortin (Christianisme et Culture philosophique au Ve siècle. Paris 1959, p. 111-123), Agustín intentará hacer admitir a sus interlocutores lo que su doctrina rechazaba absolutamente, mediante una argumentación fundada en posiciones neoplatónicas.

Objección porfiriana es todavía la que concierne a los milagros, pues no es rechazado en cuanto milagro, sino en la medida en que los que propone el cristianismo son "demasiado poco para la divinidad", menos asombrosos que los realizados por magos paganos" (M. MOREAU, o. cit. p. 127).

37. Sincera enim et solida res est nec fucatis eloquiis ambit ad animum nec ullo linguae tectorio inane aliquid ac pendulum crepitat. Multum movet non verborum sed rerum avidum 
Con estas palabras Agustín se refiere a la qualitas, es decir, contienen una valoración de la Escritura en el doble aspecto de su contenido y de su forma. En cuanto al contenido afirma que es una realidad auténtica (sincera) y sólida (solida) 38; en cuanto a la forma advierte que en vano se han de buscar en ella los artificios literarios. Esto significa que en la Escritura no es importante lo segundo, la forma, sino lo primero, los contenidos, la res ${ }^{39}$; que no hay que buscar en ella la fascinación ni el atractivo de las lindezas recomendadas por la retórica clásica, porque si impresiona y es capaz de mover y hasta procurar un horror provechoso no se debe a ellas, sino a sus contenidos; que sólo es eficaz en quienes buscan en ella lo que debe buscarse, lo que es sólido, no lo que es tornadizo y vano. Con estos juicios está indicando Agustín las condiciones de acceso fructífero a la lectura de la Escritura que acaba de recomendar.

La advertencia es oportuna. También la experiencia ajena, pero sobre todo la propia, se la inspiraba a Agustín. Tanto problemas de forma como de contenidos se habían interpuesto en su momento entre él y la Escritura. Los problemas de forma son conocidos. No es preciso detenerse en comentar lo tantas veces repetido de que las primitivas traducciones latinas de la Biblia eran muy deficientes desde el punto de vista lingüístico y literario. Agustín sintió esa dificultad, y en su tarea de expositor de la palabra de Dios se ocupó de justificar esas deficiencias como un método de la pedagogía divina, al igual que las oscuridades que, de modo idéntico, se dejan percibir. Respecto a esto último baste recordar aquí un texto de su segunda carta a Volusiano que recoge lo que es enseñanza habitual: "En cuanto al modo de expresión propio de la Escritura, ¡cuán asequible es a todos, aunque a pocos es dado penetrar en ella! Como un amigo íntimo, expresa sin artificios al corazón de doctos e indoctos las verdades manifiestas que contiene. Pero aún esos misterios que oculta no los eleva con lenguaje orgulloso a donde no se atreva a cercarse el entendimiento algo torpe o falto de preparación, como un pobre ante un rico. Por el contrario, invita a todos con palabra humilde, no sólo para nutrirlos con verdades manifiestas, sino también para ejercitarlos con verdades ocultas. Lo mismo nos dice en las expresiones claras que en las oscuras, mas para que las verdades claras no engendren fastidio, las encubre, y así excita nuestro deseo. De esta manera, con el deseo se

et multum terret factura securum. Sobre sincera aplicada a la Escritura, cf. De moribus ecclesiae catholicae I,29,61; Contra Faustum 22,79.

38. Según H. Hagendahl (Augustine and the Latin Classics. Göteborg 1967, vol II, p. 473) se trata de una reminiscencia de Persio (Satirae V,24-25).

39. Cfr. De doctrina christiana I,2,2ss. 
renuevan en cierto modo, y por la renovación nos resultan más íntimas y suaves. Por este medio los ingenios malos se corrigen, los modestos se nutren, los grandes se deleitan y todo se hace saludablemente. Sólo es enemiga de esta doctrina aquella alma que por error ignora que ésta es la doctrina salvadora o por enfermedad odia la medicina" 40.

Pero también Agustín experimentó dificultades ante la Escritura por cuestiones de contenido, y diríamos que sobre todo de contenido. En otro lugar hemos intentado probar cómo la célebre dignitas ciceroniana ${ }^{41}$ que echó de menos en la Escritura (Católica) no era primariamente un problema de forma, sino ante todo de contenido ${ }^{42}$. En efecto, que encontró la Escritura católica, bien es cierto que bajo el efecto de la propaganda maniquea, como un conjunto de incoherencias y de absurdos es dato atestiguado por el mismo Agustín. Basten algunos ejemplos en los que Agustín habla ya a agua pasada: "También me alegraba de que los antiguos textos de la ley y los profetas ya no se presentasen ante mis ojos con aquellos rasgos de antes que me parecían absurdos, cuando yo achacaba a tus santos una mentalidad de este tipo, siendo así que en realidad no pensaban de este modo...; aquellos textos que, tomados a la letra, parecían enseñar la perversidad, pero que, interpretados en sentido espiritual,... no tenían contenidos repugnantes a mi pensamiento" ${ }^{43}$. Y un poco más adelante: "Por lo que se refiere al montón de absurdos con que en ellas me encontraba... yo lo atribuía ya a la profundidad de los misterios" 44 . Más claro todavía lo indica en el texto ya citado en que menciona su encuentro con la Escritura posterior a la lectura de los neoplatónicos. Entonces comenzaron a desvanecérsele las dificultades consistentes en las contradicciones e incoherencias que veía entre Pablo por una parte o/y la Ley y los Profetas por otra. "Y apareció ante mis ojos la verdadera y única identidad de tus palabras castas" 45 . A dos se reducen, pues, las dificultades percibidas anteriormente por Agustín: la Escritura contiene falsedades y carece de unidad entre sus partes.

40. Ep. 137,5,18; Cf. también Conf. 6,5,8; De doctr. christ. 2,6,7 y J. PePIN, Saint Augustin et la fonction protreptique del'allégorie, en Recherches Augustiniennes 1 (1958) 244-257; M. PonTET, L'exégèse de saint Augustín prédicateur, Touluose 1944, p. 127ss; G. STRAuss, Schriftgebrauch, Schriftauslegung und Schriftbeweis, Tübingen 1959, p. 18. H.I. MARrou, Saint Augustin et la fin de la culture antique, Paris 1938, 484-494.

41. Conf. 3,5,9

42. P. DE LUIS, No me pareció digna de ser comparada con la dignidad de Tulio (Confessiones III 5,9), en Jornadas Agustinianas. Con motivo del XVI Centenario de la Conversión de San Agustín. Madrid 22-24 de abril de 1987. Estudio Agustiniano, Valladolid 1988, p. 4969.

43. Conf. $6,4,6$.

44. Conf. $6,5,8$.

45. Conf. $7,21,27$. 
Esas fueron las dificultades de Agustín y esas intuyó que podían ser las de su destinatario. Por eso, repetimos, se anticipa a guiarle para que no quede desorientado y sepa sobreponerse a ellas, indicándole, de un lado, que los criterios estético-literarios no son los adecuados para juzgar las Escrituras ni éstas ejercerán su eficacia sobre quienes se acerquen a ellas guiados por esos móviles. Y, de otro, insiste en que la Escritura es una realidad sincera et solida. Dos términos que nos arriesgamos a parafrasear de esta manera: dice verdad y es verdadera, consistente, maciza. Si bien la solidez está aquí ciertamente para excluir algo que caracteriza a la retórica y que él describe con términos como fucatum, inane ac pendulum, creemos que no se agota ahí la intención de Agustín, sino que alarga el significado hasta identificarlo con verdad, puesto que la solidez es su característica. Un texto tomado de las Confesiones nos puede ayudar a comprenderlo: "Esta es la situación de un alma enferma sin consolidar aún en la solidez de la verdad. Según soplen los vientecillos de las lenguas, emitidos de los pechos de los opinantes, así la traen y la llevan, la lanzan y la rechazan de manera que se le oscurece la luz y no ve la verdad" "46. Algo que no depende, pues, de las opiniones de los hombres, sino que goza de solidez y firmeza por sí misma. Solidez y firmeza que, por otra parte, coloca a la Escritura en la esfera de lo divino a que corresponden esas cualidades: "Yo sabía, Señor, que tenía que elevar mi alma hasta ti para que sanara. Pero ni quería ni podía, porque cuando pensaba en ti, no eras para mi mente algo sólido y consistente, o sea que no eras tú. Un vano fantasma y mi error eran mi Dios" 47.

La valoración de Agustín la podemos condensar en estas contraposiciones: frente al artificio (fucus), la autenticidad y verdad (sincera); frente a la volatilidad (inane) del discurso retórico ${ }^{48}$, la solidez (solida) de la palabra bíblica; frente a mutabilidad (pendulum) de las opiniones humanas, la inmutabilidad de la verdad de la Escritura.

Si es que no tenía información más precisa al respecto, Agustín intuyó que Volusiano podía experimentar las mismas dificultades que él había experimentado frente a la Escritura. Si bien éste no procedía del maniqueísmo, sí se había alimentado de la misma cultura literaria y probablemente filosófica que había formado el espíritu de Agustín. De ambos lados podía

46. Conf. $4,14,23$.

47. Conf. 4,7,12.

48. Para explicar el concepto de "vanidad" que Agustín opone al de solidez que caracteriza la Escritura, Agustín recurre al ejemplo del humo: Fumus a loco ignis erumpens in altum extollitur, et ipsa elatione in globum magnum intumescit: sed quanto fuerit globus ille grandior, tanto fit vanior; ab illa enim magnitudine non fundata et solidata, sed pendente et inflata, it in auras et dilabitur, ut videas ipsam ei obfuisse magnitudinem (En in psalmum 36, 2, 12). 
surgir la censura contra los Libros inspirados. A partir de esa intuición, si no conocimiento exacto, creyó oportuno enseñar a su interlocutor qué es importante y qué no lo es en la Escritura, qué se ha de buscar en ella y qué no, y mostrarle el método justo como acercarse a ella y sacar provecho de dicho acercamiento. De ese modo le evitaría sorpresas inesperadas de carácter negativo.

\section{d) Orden de lectura}

Agustín no se limita a exhortarle a que lea la Sagrada Escritura. El va más allá, hasta indicarle expresamente, siempre a nivel de exhortación, el orden que debe seguir en dicha lectura. Así escribe: "Te exhorto a que leas con preferencia los escritos apostólicos, pues por ellos te animarás a conocer los profetas, de cuyo testimonio usan los apóstoles" 49.

Una primera observación se refiere al significado del término "escritos de los apóstoles". El plural "apóstoles" nos obliga a entenderlo de todo el Nuevo Testamento, no ya de sólo Pablo. El empleo del genérico linguas, traducido aquí por "escritos", en vez de epistulae hace que incluyamos no sólo las cartas apostólicas, sino también a los evangelios, no obstante que no todos sean obra de "apóstoles".

Cabe ahora preguntarse por el fundamento de dicha exhortación. ¿Qué pudo haberle sugerido a Agustín el hacerla? No hay duda de que el carácter mismo de la Escritura, que Agustín define como una selva inmensa 50 en la que es difícil entrar, hacía lógica la recomendación. Los problemas de forma y de contenido que, como recordamos, fácilmente podían aparecer, hacen más que comprensible que el pastor Agustín ofreciese pistas de acceso para obviarlos. Una lectura sin orientación, como fue la primera suya, tras la del Hortensio, le condujo fuera de la fe católica en que había sido educado por su madre. Se encontró sin medios de defensa ante las numerosas dificultades.

Pero podemos pensar en algo más concreto, centrado nuevamente en la experiencia de Agustín. Está indicado en este texto: "Por medio de una carta le di a entender a tu obispo, el santo varón Ambrosio, mis errores pasados y mi opción actual, rogándole que me aconsejase cuál de los libros sería prefe-

49. Praecipue apostolorum linguas exhortor ut legas; ex his enim ad cognoscendos prophetas excitaberis, quorum testimoniis utuntur apostoli. Cuando Agustín se dirige a Ambrosio para que le indicase qué debía leer como preparación al bautismo, éste responde no con una exhortación, sino con un mandato (iussit) (Conf. 9,5,13).

50. Conf. 11,2,2. 
rible para mis lecturas, en vistas a una preparación más adecuada para recibir una gracia tan grande. Me prescribió la lectura del profeta Isaías, porque, según creo, es entre todos los profetas el que preanuncia con mayor claridad el evangelio y la vocación de los gentiles. Pero al no entender lo primero que leí y al pensar que todo el resto sería igual, diferí su lectura para más adelante, cuando estuviese más adiestrado en el lenguaje del Señor" 51.

En su deseo de prepararse adecuadamente para el bautismo durante su retiro en Casiciaco, Agustín piensa en la lectura bíblica como un medio apto. Pero ¿qué parte puede serle de mayor provecho? Es preciso conocerla en su totalidad para poder elegir un libro y no otro. Considera que Ambrosio, quien sin pretenderlo explícitamente le había devuelto la confianza en la Escritura católica, y lector y comentador asiduo de ella, le puede encauzar al respecto. A él, pues, se dirige por medio de una carta, situándole en antecedentes que puedan orientar su consejo. Ambrosio le aconseja la lectura del profeta Isaías. Agustín conjetura el motivo: porque es el que de forma más clara anuncia la vocación de los gentiles ${ }^{52}$. Apenas abierto, Agustín cerró el libro, por no hallarsẹ en disposición de entenderlo. Necesitaba, dice, tiempo y práctica para habituarse al "lenguaje del Señor" 53.

A esta experiencia personal sobre todo puede atribuirse la recomendación que nos ocupa de Agustín a Volusiano de comenzar la lectura por los escritos apostólicos. Una elección equivocada podría dar al traste con las esperanzas que se ponían en dicha lectura. Agustín pudo pensar con razón que sí él había hallado insoportable la lectura de los profetas, lo mismo le podía suceder a su destinatario. No quiere que se repita en este caso la equivocación que experimentó en su persona. Por eso le invita expresamente a leer con preferencia los escritos apostólicos.

Ya dijimos con anterioridad que bajo tal expresión parece que deba entenderse todo el Nuevo Testamento. Pero al mismo tiempo, no estaremos

51. Conf. 9,5,13.

52. Las posibles razones por las que San Ambrosio ordenó (iussit) a Agustín leer al profeta Isaías las expone C.L. Ferrari en Isaiah and the early Augustine, en Augustiniana 41 (1991) 739-756. En síntesis, helas aquí: la que conjetura el mismo Agustín (el más claro exponente de la vocación de los paganos); la predilección de Ambrosio por Isaías, el profeta más citado por él y sobre el que probablemente acababa de escribir un comentario; probar la fe del maniqueo convertido repentina y sospechosamente. La lectura de Isaias fue "the proverbial acid test of sincerity os Augustine's claimed conversion to catholicism" (p.744).

$53 \mathrm{El}$ mismo C.L. Ferrari en el artículo citado en nota anterior concluye (p.746), tras analizar varios datos de las Confesiones que naturalemente deberían concluir en la capacidad de Agustín para entender al profeta Isaías, que si Agustín no lo entendió fue porque no estaba interesado en entenderlo, como consecuencia del trasfondo maniqueo que aún pesaba sobre él. 
lejos de la verdad si pensamos que Agustín tenía en la mente de un modo particular al apóstol Pablo. Aunque propiamente se trata sólo de una conjetura por falta de explícito apoyo textual, hay razones que permiten pensar que sea así. La primera, de carácter general, es el paralelismo que venimos estableciendo entre las Confesiones y la carta 132. Por una parte, viene a la mente el texto, ya citado, del libro séptimo en que refiere su lectura posterior al encuentro con los neoplatónicos: "Con toda avidez, cogí las Escrituras venerables de tu Espíritu, con preferencia el apóstol Pablo" 54. Por otra, Agustín tenía motivos más que suficientes para pensar sobre todo en Pablo. Son los siguientes: a) motivos literarios; b) motivos de actualidad; c) motivos de oportunidad.

a) Motivos literarios. Aunque Agustín ha anticipado que la Escritura no hay que valorarla por criterios artístico-literarios, queda en pie que a un hombre que sabe apreciar esos valores siempre le será más fácil leer algo que no esté desprovisto de ellos. Ahora bien, en la obra De doctrina christiana trata de demostrar que se puede afirmar de los autores sagrados que escribieron con tanta sabiduría como elocuencia. Una elocuencia, cierto, que se ajusta a las condiciones particulares, pues ni a ellos les convenía otra ni la suya convenía a otros; elocuencia que se caracteriza -y nos hallamos en lo indicado con anterioridad en la carta- por la solidez en oposición a la "ampulosidad". "Pues así como hay cierta elocuencia que es más propia de la edad juvenil, y otra que conviene a la senil, y no puede recibir el nombre de elocuencia si no se ajusta al orador, así también hay una elocuencia que conviene a estos hombres dignísimos de suma autoridad y claramente divinos. Con esta autoridad hablaron aquellos autores sagrados, y ni a ellos convenía otra, ni a otros convenía ésta, pues es a ellos a quienes se ajusta; mas por lo que respecta a los otros, cuanto más humilde les parece, tanto más los supera no por su ampulosidad (ventositate), sino por su solidez (soliditate)" 55.

A pesar de todo, después de marcar las diferencias entre las dos clases de elocuencia, la profana y la de los autores sagrados, Agustín se esfuerza en mostrar que en ningún modo éstos están desprovistos de aquélla, y los ejemplos que aporta para mostrarlo están tomados preferentemente del apóstol Pablo, quien no carece, según él, de los recursos literarios, incluida la oportuna variatio en los estilos, acomodada a las diversas circunstancias de tema

54. Conf. 7,21,27.

55. De doctr. christ. 4,6,9. 
y auditorio ${ }^{56}$. Leyéndole, Volusiano no se encontrará alejado de lo que él aprecia.

b) Motivos de actualidad. Los que queremos expresar está perfectamente recogido en este texto de M.G. Mara: "En la segunda mitad del s. IV y al comienzo del $\mathrm{V}$ asistimos al surgir de numerosos comentarios latinos a las cartas de Pablo: desde el comentario de M. Victorino al del Ambrosiaster, del de Jerónimo al de Agustín, de Pelagio, de Julián de Eclana. El fenómeno no es casual. Aparece en efecto como el intento de ofrecer la persona de Pablo como modelo de conversión y de vida en un momento en que las disputas teológicas, divinizando demasiado a Cristo, lo habían secuestrado a la piedad popular y habían hecho inaccesible y lejana su imitación; y puntualizando más el fenómeno, aparece como el intento de responder a los interrogantes puestos por aquella situación de angustia que se difunde al inicio de la decadencia del mundo antiguo y, concretamente, a las preguntas que surgían de varias partes sobre: ¿cómo puede el hombre salvarse y qué hombre se salva? Esta era la pregunta de Agustín, pero no solo la suya. En la segunda mitad del s. IV la respuesta a la demanda de salvación presente en los hombres parece alcanzar particular urgencia ya pór el número de cuantos se ponen tal pregunta, ya por los ambientes de donde provienen cuantos miran al cristianismo. Y Pablo, más que cualquier otro autor del Nuevo Testamento, con la historia de su conversión, con el contenido teológico y ético de su epistolario, se convertía en la referencia más cualificada para hacer conocer, con la eficacia que se atribuía a la Palabra de Dios, la vocación universal de los hombres a la salvación y la contribución de cada uno a la propia historia salvífica. En otras palabras, la antropología paulina y de los comentadores de Pablo consentía, en una pluralidad de situaciones culturales y existenciales, la unidad esencial y las diversificaciones posibles" 57 .

c) Motivos de oportunidad. Ya indicamos con anterioridad cómo los encuentros más decisivos de Agustín con la Escritura fueron específicamente encuentros con S. Pablo; más importante el primero que el segundo. S. Pablo, leído con avidez, fue el complemento necesario a la lectura previa de

56. De doctr. Christ. 4,7,11ss. Ciertamente este texto es tardío, pero recoge el pensamiento muy anterior de Agustín. Cf. el primer libro de su obra Contra Cresconium donde hace una defensa de la elocuencia y dialéctica, en concreto de la de Pablo. Tras citar 2 Cor 6,4-10, continúa: ¿Quid enim hoc stilo apostolico uberius et ornatius, id est eloquentius, facile invenis? $(1,15,19)$. La obra fue escrita hacia el 405.

57. M. G. MARA, La conversione di Agostino e la fine del mondo antico, en Conversione e storia. Augustinus, Palermo 1987, p. 47-48. Cf. de la misma autora, L'influsso di Paolo in Agostino, en J.RIES - F.DÉCRET - W.H.C.FREND - M.G.MARA, L'epistole paoline nei manichei $i$ donatisti e il primo Agostino, I.P. Augustinianum, Roma 1989, pp. 125-162; esp. 138139. 
los neoplatónicos ${ }^{58}$. Esta se presentó a Agustín como una tentación ${ }^{59}$, que fue superada gracias a la lectura posterior de San Pablo. Volusiano y los compañeros del círculo se encontraban en la misma situación que Agustín en aquel período; cultores de la filosofía del momento ${ }^{60}$ corrían el riesgo de conceder todo a la filosofía en lo que a la salvación del hombre se refiere. Agustín señala muy bien lo que de complemento bíblico exigía la lectura de los libros neoplatónicos al escribir: "Nada de esto contienen aquellos libros. Sus páginas no tienen este semblante piadoso, ni lágrimas de confesión, ni tu sacrificio, ni un alma angustiada, ni un corazón contrito y humillado, ni la salvación de tu pueblo, ni la ciudad esposa, ni las arras del espíritu, ni la copa de nuestro rescate. En aquellas páginas nadie canta: ¿Es que mi alma no va a someterse a Dios? De él viene mi salvación. El es quien me acoge, no vacilaré jamás. Nadie escucha allí la voz invitadora: Venid a mí todos los que estáis cansados... Una cosa es contemplar desde la cima frondosa la patria de la paz, sin hallar el camino que conduce hacia ella, tras vanas tentativas de ensayar atajos perdidos, expuestos a las asechanzas de los desertores guiados por su jefe... y otra cosa muy distinta es mantenerse en el camino que conduce a ella, guarnecido bajo la supervisión del emperador del cielo, donde no hay asaltos de los desertores de las milicias del cielo, que evitan ese camino como un suplicio. Estos pensamientos se iban encarnando en mis entrañas de una manera sorprendente, mientras leía al último de tus apóstoles" 61. Las múltiples citas implícitas de este texto exceden ciertamente las páginas paulinas, pero se trata de una valoración del Agustín ya obispo que escribe, mientras el dato central a que se refiere es la lectura preferencial de Pablo. En síntesis, cabe suponer que Agustín recomienda a Volusiano el remedio que le sirvió a sí mismo ${ }^{62}$.

Pero Agustín no olvida a los profetas. También aquí es correcto comenzar preguntándose por la amplitud del término. Puede significar globalmente el Antiguo Testamento o específicamente a los designados por ese nombre en la tradición cristiana. Por paralelismo con lo expuesto con anterioridad respecto a los escritos apostólicos lo lógico es pensar en las dos cosas a la vez.

58. Conf. 7,21,27.

59. Conf. $7,20,26$.

60. Cfr. n. 36.

61. Conf. 7,21,27.

62. "El deseo de poner en relación a Pablo con el neoplatonismo para facilitar a los paganos cultos el acercamiento a los textos sagrados se halla, de hecho, tanto en el Epistolario apócrifo de Séneca y San Pablo como en los comentarios paulinos de C.M. Victorino" (M.G.MARA, L'influsso, p. 140). 
El presenta su lectura casi como un corolario de la de los apóstoles. En efecto, los escritos apostólicos que se sirven de ellos, escribe, le estimularán a dar ese paso. Agustín, pues, muestra interés en mantener la lectura de los profetas. Cabe preguntarse por qué. Una posible respuesta consistiría en ver en el hecho el deseo de respetar y valorar a posteriori el consejo de su maestro San Ambrosio. Un modo eficaz era repetirlo él. En este sentido, Agustín habría querido marcar el mismo camino a Volusiano, que también procedía de la gentilidad. Mas, para evitar que le sucediese lo que le aconteció a él, le otorga la llave para su comprensión: comenzar por la lectura de los escritos apostólicos. El paso de estos escritos a los de los profetas es natural, dada la dependencia mutua. El evento permite comprender la profecía y, una vez comprendida la profecía, se ahonda en la comprensión del evento.

Pero esta explicación es excesivamente formal. Agustín aparece como esclavo de un modelo, aunque sea el propio personal. De ser así se asemejaría a quien recomienda un medicamento más o menos eficaz en su caso particular, olvidando que el otro puede presentar un cuadro clínico distinto ${ }^{63}$. Pero Agustín no hubiese ofrecido tal receta a Volusiano de no saber que necesitaba esa precisamente. Es lógico, pues, pensar que el Obispo de Hipona, en el momento de escribir dicha recomendación conoce o intuye alguna dificultad del destinatario de su carta con los profetas, ya en sentido amplio, ya en el sentido más restringido. ¿Podemos especificarla ya en concreto?

Una posible respuesta nos la sugiere la carta de Marcelino a Agustín. El oficial romano informa al obispo de Hipona de que en aquel círculo de intelectuales se criticaba el cambio de la economía de la Ley antigua a la de la Ley nueva con estas palabras: "Decía que... apenas podrían explicarle por qué ese Dios, que se dice era también Dios en el Antiguo Testamento, despreciando los antiguos sacrificios, ha preferido otros nuevos. Aseveraba que nada puede corregirse en modo alguno. Decía que el cambiar las cosas que han sido bien instituidas es contrario a la justicia; especialmente cuando esa vanidad podría demostrar inconstancia en Dios" 64. Agustín conocía sin duda las objeciones a la fe cristiana procedentes del mundo pagano ${ }^{65}$. Al establecer la lectura tanto de los apóstoles como de los profetas es posible que le guiase el deseo de que a través de ella percibiese la unidad esencial entre ambos Testamentos, conforme a la respuesta que da en su carta a Marcelino ${ }^{66}$. Es tal la unidad entre ellos que los apóstoles remiten a los profetas;

63. Cfr. el ejemplo que pone Agustín en Epist. 138,1,3.

64. Epist. 136,2.

65. Cf. P. COURÇELLE, Propos antichrétiens rapportés par saint Augustin, en Recherches Augustiniennes 1 (1958) 149-189.

66. Epist. 138,1,2-8. 
más aún, la simple lectura de los primeros estimula (excitaberis) a la de los segundos.

Otra posible respuesta nos la sugiere la segunda carta de Agustín a Volusiano. En ella hace referencia a las "verdades útiles que dijeron no sólo los profetas, que siempre hablaron verdad, sino también los filósofos y los mismos poetas y cualesquiera otros hombres de letras, que, como todos saben, mezclaron muchas cosas verdaderas con otras falsas" ${ }^{67}$. Esta realidad tiene su formulación en la expresión tan querida de Agustín "el oro de los egipcios", que menciona incluso en el libro séptimo de las Confesiones en conexión con la lectura de los neoplatónicos: "Yo había llegado a ti procedente de los gentiles y puse mis ojos en el oro que quisiste que tu pueblo sacase de Egipto, porque este oro, dondequiera que se hallara, era tuyo" 68. El tema está vinculado a la concepción, procedente ya de la apologética anterior a él, de que los sabios antiguos de la gentilidad se habían inspirado en los profetas anteriores a ellos. En este contexto, Agustín pretendería que Volusiano viese la continuidad existente entre la sabiduría cristiana y la pagana que él cultivaba.

Así, pues, supuesto que Agustín hubiera querido hacer honor a su maestro Ambrosio al mantener la referencia a los profetas, oportuna, por otra parte, desde la situación personal de Volusiano, le corrige en lo que personalmente había percibido como una equivocación. La lectura de los profetas es provechosa, pero no se ha de comenzar por ellos. Si a él no le produjo efecto negativo, la necesidad en que se vio de cerrar el libro se debió a que le llegó en el momento entusiasta de la conversión recién acontecida; peligroso podía ser para quien aún estaba en camino hacia ella. Ese peligro lo quiso conjurar recomendando a Volusiano que iniciase su lectura por los escritos apostólicos.

\section{e) Contacto epistolar}

Agustín tampoco se queda en la recomendación de un orden de lectura. Sus consejos van todavía más lejos. Leamos la conclusión de la carta: "Y si en tu lectura o meditación te surge algún problema para cuya solución pueda yo parecerte necesario, escríbeme y te contestaré. Quizá, con la ayuda de Dios, podré hacer mejor eso que hablar cara a cara contigo. Y no sólo por

67. Epist. $137,3,12$.

68. Conf. 7,9,15; véase también De doctr. christ. 2, 40,60-61; Contra Faustum 22,91. Cfr. asimismo OrIGEnes, Carta a Gregorio, PG 11,88-89; Jeronimo, Epist. 21,13; 70,2. 
las múltiples ocupaciones, tanto tuyas como mías (pues cuando yo tenga alguna holgura no la disfrutarás tú), sino por la inevitable presencia de aquellos que generalmente no están preparados para eso, y se gozan más en combates de palabra que en la luz de la ciencia. En cambio, lo que se tiene escrito, siempre está dispuesto para la lectura en cuanto queda desocupado el lector. Además, aunque esté presente, no resulta gravoso; si quieres lo tomas, y si quieres lo dejas" ${ }^{69}$.

El texto, un tanto largo esta vez, pide que lo desglosemos en sus partes. El primer dato se refiere a la posibilidad de que existan problemas de comprensión. Posibilidad que está abierta siempre que un hombre se encuentra con cualquier texto o concepto, y en ese sentido el aviso de Agustín se puede justificar desde la simple condición humana. Pero una vez más nos hallamos con que a Agustín le inspira su experiencia personal. Ya citamos el texto en que indicaba cómo por no entender al profeta Isaías tuvo que cerrar el libro ${ }^{70}$. Aunque él ha tomado las precaución de introducirle por un camino más fácil, la posibilidad de extravío sigue abierta y por eso se apresta a ofrecerle sus servicios para reconducirle al camino, si fuera necesario, y al mismo tiempo le indica el modo cómo hacerse con ellos.

Un segundo dato es el ofrecimiento personal de Agustín para solucionarle sus problemas. También aquí cabe pensar que el ofrecimiento surja como resultado de su propia experiencia. Lo que él echó de menos es lo que ahora ofrece. Es curioso que al leer al profeta Isaías y no entenderlo no tomó otra decisión sino la de cerrar el libro y esperar. Parece como si hallase cerrada la posibilidad de que alguien le prestase ayuda. Al menos no piensa en ella; probablemente influyó el hecho de hallarse en el campo, un tanto alejado de la ciudad, lo que no facilitaba el contacto con Ambrosio que sin duda podía brindarle soluciones. Quizá se debió a falta de confianza en Ambrosio con quien siempre mantuvo relaciones un tanto distantes 71 ; con

69. Si quis autem vel cum legis vel cum cogitas, tibi oritur quaestionis, in quo dissolvendo videar necessarius, scribe, ut rescribam. Magis enim hoc forte adiuvante domino potero quam praesens talia loqui tecum non solum propter occupationes varias et meas et tuas, quoniam non, cum mihi vacat, occurrit, ut ut tibi vacet, verum etiam propter eorum inruentem praesentiam, qui plerumque non sunt apti tali negotio magisque linguae certaminibus quam scientiae luminibus delectantur. Quod autem scriptum habetur, semper vacat ad legendum, cum vacat legenti, nec onerosum fit praesens, quod, cum voles, sumitur, cum voles, ponitur.

70. Conf. 9,5,13.

71. "Es difícil comprender por qué Agustín, teniendo interés en consultar sus problemas con Ambrosio y.ocasiones para hacerlo, no se atrevió a hacerlo. Las razones que da en sus Confesiones: no molestar a un hombre tan ocupado o tan embebido en la reflexión dejan insatisfecho al lector. O'Meara alude a una extraña reserva de Agustín frente a la personalidad de Ambrosio. Pero eso no es explicar la cuestión, sino plantarla en otros términos. También alude al sentimiento de que Ambrosio no era el hombre adecuado para ofrecerle la sín- 
otras palabras, quizá no se atrevió a molestarle, como le sucedió en tiempos pasados ${ }^{72}$. Por eso Agustín ahora quiere que Volusiano no se encuentre en la situación de desamparo en que se sintió él, y por eso se adelanta a ofrecerle sus servicios. Contando con la oferta por parte del obispo él ya no ha de sentir reparo alguno.

Un último dato: Agustín sugiere que el contacto sea epistolar más que cara a cara. La sugerencia -no resulta difícil comprenderlo- podría estar motivada por el hecho de que Agustín residía en Hipona, mientras Volusiano y su círculo de amigos estaban en Cartago. Pero el argumento no parece convincente del todo por la sencilla razón de que si bien no sabemos si Volusiano viajaba mucho o no, de Agustín sí sabemos que Cartago fue su segunda ciudad de residencia, sobre todo en el período al que corresponde la carta ${ }^{73}$. El aduce dos razones: la escasez de tiempo de una $u$ otra parte o de las dos, y la presencia de curiosos que están movidos por otros objetivos.

Es comprensible el argumento de la escasez de tiempo en un hombre tan activo como Agustín. Pero podemos pensar, una vez más, que Agustín está hablando desde la experiencia personal negativa que tuvo en su intento de contacto personal con Ambrosio. Recordemos los textos que nos aportan datos personales suyos. Uno de ellos es el siguiente: "Lo cierto es que a mí no se me concedía un resquicio ni la oportunidad de consultar a aquel santo

tesis de doctrina filosófica y religiosa a que aspiraba con su alma. Esto es ya una explicación. Ambrosio no era un hombre que tratase a los filósofos con muchos miramientos, sobre todo cuando comparaba sus doctrinas con la luz de la revelación bíblica. En cualquier caso siempre es difícil explicar el sentimiento que nos impide abrir la conciencia a una determinada persona y manifestarle los problemas íntimos, por muy capacitada que esté para resolverlos. La razón que da Agustín, aunque nos deje insatisfechos, no está desprovista de peso: Mis inquietudes exigían un hombre muy desocupado, al que pudiera expresarlas, y nunca lo encontraba" (J.m. RodrigueZ, en Le Confessioni Agostino d'Ippona - Libri VI-IX, Palermo, p. 21-22).

72. "Ambrosio, pues, no tenía tiempo, pero quizá tampoco tenía voluntad de ocuparse de las intrigas especulativas y de los enredos espirituales de este complicado intelectual, capaz de las más sotiles acrobacias dialécticas e incapaz finalmente de ponerse a vivir en modo justo y digno... Un hombre como Agustín habría pretendido para sí jornadas enteras de paciente confrontación intelectual y de análisis filosóficos municiosos, y un hombre con el temperamento de Ambrosio no tenía ciertamente ni el modo ni el gusto de embarcarse en este empresa (G. BIFFI, Conversione di Agostino e vita di una Chiesa, en Agostino e la conversione cristiana, Augustinus, Palermo 1988, p. 26-27).

73. "Refiriéndonos a J.L. Maier (O. Perler, Les voyages de saint Augustín, p. 156-162), podemos dar como seguro que Agustín se halla en Cartago primeramente en el 411, desde el 14 de mayo (sermón 269) como muy tarde hasta finales de setiembre... Vuelve a Hipona a comienzos del otoño y permenece allí durante la primera mitad del 412 . Este período de tiempo corresponde exactamente a aquel en que fueron escritas estas cartas... Luego se le vuelve a encontrar en Cartago a finales del 412, y allí permanece bastante tiempo del año 413 hasta la muerte de Marcelino" (M. MoreAu, o. cit. p. 52). 
oráculo tuyo, que era su pecho, los asuntos que yo quería, a no ser que me contestara con una respuesta concisa. El caso es que mis inquietudes reclamaban una persona muy desocupada a quien dirigir mis consultas, pero esta persona no era precisamente él" 74 . He aquí un deseo y hasta una necesidad no satisfechos, y no por culpa de Agustín, sino debido a la ocupación permanente del obispo.

Pero otro texto nos explicita más el anterior: "Me era prácticamente imposible abordarle en plan de consulta sobre los puntos cuya prioridad había establecido yo. Tampoco podía hacerlo como era mi intención. De su audiencia y de sus palabras me tenía marginado todo un montón de negocios humanos a cuya urgencia y atención prestaba sus servicios. Cuando quedaba libre de ellos, a intervalos muy breves, sin duda, reponía fuerzas con el alimento imprescindible o nutría su espíritu con la lectura. Al leer pasaba su vista por las páginas, mientras su mente penetraba en el sentido de las palabras, sin pronunciarlas ni mover la lengua... Muchas veces le vi leer en silencio. Nunca le vi hacerlo de otro modo. Yo me quedaba largo rato sentado en un silencio interminable - ¿quién iba a atreverse a interrumpir tanta concentración? Al fin, optaba por marcharme, con la fundada sospecha de que esos ratitos que se iba agenciando para el cultivo de su espíritu, libre de la barahúnda de los negocios ajenos, no quería ocuparlos con otros temas" 75 . La escena está muy bien dibujada y corresponde a un hombre tímido ${ }^{76}$ por una parte y por otra tan amante de la cultura que es incapaz de interrumpir a un hombre que está leyendo.

Luego intenta Agustín dar la explicación conjeturada de esa, para él extraña, lectura en voz baja. Una razón podía ser el deseo de conservar la voz para la predicación. Otra: "Quizás leyera mentalmente en evitación de que cualquier posible oyente, atento y entusiasmado por la lectura, le expusiera la necesidad de explicar algún pasaje oscuro del autor leído o la urgencia de plantear cualquier otro tema de mayor complejidad. Al gastar el tiempo en este menester, se habría visto obligado a leer muchos menos libros de los que tenía proyectado leer" 77.

74. Conf. $6,3,4$.

75. Conf. 6,3,3.

76. "Una extraña timidez, que nos parece bien ajena al carácter habitual de Agustín, le impide plantearle sus problemas. El incansable y ardiente buscador de la verdad no parece estar dispuesto a grandes sacrificios para alcanzarla (6,3,3-4) (J.M. RoDRIGUEZ, en Le Confessioni Agostino d'Ippona - Libri VI-IX, Palermo , p. 10).

77. Conf. 6,3,3. 
La queja de la falta de tiempo de Ambrosio vuelve a aparecer más adelante: "Pero ¿dónde y cómo busca la verdad? Ambrosio no dispone de horas libres. Yo no tengo tiempo para leer... El horario de la mañana lo tengo ocupado con la atención al alumnado. ¿Y qué hago con el resto del tiempo? ¿Por qué no emplearlo en estos menesteres? Pero, en ese caso, ¿cuándo voy a saludar a los amigos importantes, cuya ayuda tanto necesito? ¿Cuándo preparar los temas que me compran los alumnos? ¿Cuándo reparar energías y aliviar la tensión mental producida por las preocupaciones? ${ }^{78}$.

Estos textos nos ofrecen la experiencia personal de Agustín que podemos sintetizar de esta manera: Agustín, agobiado de problemas, desea entrevistarse con Ambrosio para hablar detenidamente -como con Fausto 79- de esos mismos problemas, pero no lo consigue. Ante todo por falta de decisión personal, debida quizá a la timidez, favorecida por la falta de tiempo o suya personal o de Ambrosio, ocupado o bien en arreglar asuntos humanos o en la lectura, que precisamente hace en voz baja para evitar ser interrumpido con cuestiones variadas y complejas.

La segunda razón aludida era, recordamos, la presencia de curiosos. ¿A qué se refiere? Hallamos dos pistas de solución. Una recurriendo a las Confesiones y otra a la carta a Volusiano.

En el texto antes citado de las Confesiones nos hablaba de que uno de los motivos por lo que Ambrosio solía leer en voz baja era el deseo de no ser interrumpido por curiosos allí presentes, cuyos intereses obviamente serían diversos, no faltando, podemos imaginar, quienes formados en la retórica planteasen problemas de retórica en una lectura de un libro teológico ${ }^{80}$. El dato nos permite quizá comprender una de las razones por las que Agustín desaconseja el contacto cara a cara. Siempre queda difícil de comprender por qué no podían retirarse a un lugar privado.

La carta de Volusiano nos le muestra como formando parte de un círculo de amigos de intereses combinados. Es lógico pensar que a Volusiano le resultase difícil reunirse con Agustín a solas para tratar temas que sólo genéricamente podían ser del interés del grupo. Admitir esta explicación supone que Agustín conocía ya el entorno y las circunstancias en que se movía Volusiano, cosa que no sabemos a ciencia cierta, aunque sí es lícito suponerlo, puesto que ya aludimos a un contacto previo.

78. Conf. $6,11,18$

79. Conf. 5,6,11.

80. No era extraño que "estudiantes" conocedores de la cultura y amabilidåd del obispo se dirigiesen a él para consultas de carácter técnico-retórico. Con referencia a Agustín tenemos los ejemplos del pagano Máximo y de Dióscoro (epist. 16-17 y 117-118). 
Sea cual sea la explicación acertada ambas a dos hacen más comprensible la de la carta. En primer lugar es un hecho innegable la permanente ocupación de Agustín, que no siempre encontraría el tiempo que dedicar a Volusiano, en el caso, no siempre probable, de que éste dispusiese de él. En consecuencia, la mejor solución era plantear los problemas por correspondencia epistolar, que no requiere la presencia física de los dos al mismo tiempo. En segundo lugar, Agustín quiere centrar el diálogo en lo que le interesa a él, la cuestión religiosa. Ahora bien, si se hace cara a cara, difícilmente estarían ausentes o bien los curiosos de turno o bien los amigos del grupo que podían hacer desviar el tema de conversación hacia otros aspectos más formales o poner todo el esfuerzo en exhibir la propia elocuencia, sin demasiado atención al contenido (certamina linguae). Ambrosio evitaba ese desvío impidiendo mediante la lectura en voz baja la intervención de otros; Agustín, que está sumamente interesado en mantener el diálogo con Volusiano, llevando el tema por carta. Este interés de Agustín hay que resaltarlo una vez más. Quizá hasta intuye que Volusiano esté deseando ese encuentro, cómo él lo deseó en su época milanesa; y para evitar que no se lleve a cabo arbitra la fórmula que considera más eficaz desde la situación concreta. Para una carta siempre hay tiempo, sino es en un momento es en otro. Como dice expresamente Agustín: "En cambio, lo que se tiene escrito, siempre está dispuesto para la lectura en cuanto queda desocupado el lector. Además, aunque esté presente, no resulta gravoso; si quieres lo tomas, y si quieres lo dejas".

En definitiva, una vez más, recuerdos personales pudieron haber dictado las últimas líneas de la carta. Pero con la particularidad de que en este caso a los recuerdos van unidas algunas frustraciones, que Agustín desea evitar a Volusiano. Agustín quiere presentarse, valga la expresión, como un nuevo Ambrosio, para el nuevo Agustín, esta vez Volusiano. Pero un Ambrosio con un talante nuevo.

$$
* * *
$$

Si hemos logrado convencer a nuestros lectores, se pueden extraer las siguientes conclusiones, referidas a los siguientes puntos: a) La historicidad de las Confesiones. b) El camino de Agustín hacia la fe verdadera. c) El camino de Agustín, propuesto a Volusiano.

\section{a) La historicidad de las Confesiones.}

En su obra Recherches sur les Confessions de saint Augustin, el sabio francés P. Courcelle demuestra la historicidad global de las Confesiones, 
recurriendo a textos paralelos del resto de la amplia producción del Santo. Pues bien, en dicha obra no se cita ni una sola vez su carta 132, a juzgar por el índice. No sabemos si por inadvertencia de los paralelismos que hemos mostrado o porque no consideró los textos presentados con la suficiente solidez como para mantener las conclusiones extraídas por nosotros. En todo caso, la carta no es un texto raro que fuese de difícil consulta. No nos referimos a la materialidad de hallarlo, sino al hecho de juzgarlo de valor. Todo el epistolario, en efecto, tiene el máximo valor autobiográfico. Por nuestra parte, creemos que el hecho de que se pueda comentar la totalidad de la carta, al menos en su estado actual, con textos paralelos tomados de las Confesiones, como acabamos de hacer, otorga un alto nivel de probabilidad y podemos considerar la carta 132 como un documento más a añadir a los aportados por P. Courcelle en favor de la historicidad de las Confesiones. El hecho no está en discusión, pero nunca está demás una prueba ulterior.

\section{b) El camino de Agustín hacia la fe verdadera.}

La misma carta nos aporta otra información sobre Agustín correspondiente a un nivel más interno. A la vez que vive su vida va reflexionando sobre ella. En este sentido las Confesiones no han de ser consideradas como una obra puramente circunstancial sino como el fruto de esa reflexión profunda y permanente. En esa reflexión descubre unos momentos centrales que son la clave de entendimiento de todo lo demás: en el principio de todo, podríamos decir, estuvo su madre orante; en el centro halló la Escritura, que en un primer momento no fue capaz de entender en su realidad sustancial, y que sólo con la ayuda externa y eclesial consiguió. Nos encontramos con una doble mediación, la humana y la de la palabra, de que se sirve Dios. En realidad, en el principio está la obra de Dios propiciada por la oración que brota del amor humano y cristiano de su madre; en el centro está también Dios en su palabra pidiendo el esfuerzo de lectura y meditación a la persona a que llama al diálogo con él. Esfuerzo que incluye siempre un cierto despojo personal.

La Escritura está puesta entre el hombre y Dios, como camino que une a ambos. Mas para que pueda cumplir su función es imprescindible valorarla en su realidad propia y no desde criterios que le son ajenos. Sin duda está condicionada por el sujeto que se le acerca. La afirmación tiene un doble sentido, indicando una relación positiva y otra negativa; positiva, porque tiene distintos niveles de comprensión que se acomodan a la situación concreta del lector; negativa, si se mira desde este lector: corre el riesgo de 
medirla, en lugar de dejarse medir; de constituirse en juez, en vez de dejarse juzgar por ella y utilizar códigos que no le cuadran. Lenguaje de Dios que es difícil, cuya comprensión no está al alcance de quien no está avezado en su trato. Es fácil que aparezca la tentación de poner uno mismo las claves de lectura. Pero se trata de una tentación que es preciso vencer. Por eso el esfuerzo de lectura incluye siempre un cierto despojo personal, un dejar de lado las propias vaciedades.

Este despojo personal lleva consigo la exclusión de toda autonomía en el esfuerzo de comprensión. Al inicio del camino, la simple lectura personal es arriesgada y puede llevar al fracaso total. Se impone la mediación eclesial. El pastor que aclara los pasajes difíciles no es el sabio a título personal, sino el portavoz de la fe de la Iglesia. El, el pastor, está al servicio de esa Escritura, no al revés.

\section{c) El camino de Agustín, propuesto a Volusiano.}

En las Confesiones dice que escribe no para Dios, sino para los demás ${ }^{81}$. $\mathrm{Su}$ historia particular es sólo concreción de un camino más general. Por eso aplica a Volusiano su propio caso. En cuanto alejado de Dios, el abismo en que se encuentra Volusiano es el mismo en que se encontró él. Para que salga a la luz, le ofrece la ruta seguida por él. En el principio está la madre que anhela la salud del hijo y ora por ella. En el caso de Volusiano es ya una realidad.

En el centro está la Escritura: de aquí la invitación que le hace Agustín a leer esa Escritura. Escritura que le presenta como santa, auténtica y sólida; en consonancia con ella, solicita de Volusiano un espíritu abierto a sus contenidos, más allá de toda preocupación exclusiva por la forma. Le ofrece igualmente una puerta de acceso, por la que hallará menos dificultades: los escritos apostólicos. Y le recuerda que, una vez dentro, se encontrará, como señalización oportuna, con que los escritos apostólicos remiten a los proféticos, a cuya lectura se entregará a continuación. Con todo, las dificultades son inevitables y harán acto de presencia; no las debe dejar dormir, antes bien, ha de buscarles solución. Pero esa solución no la ha de confiar a cualquiera, sino a quien pueda ofrecerla en consonancia con las características de la misma Escritura. Esto sólo tiene lugar dentro de la Iglesia. De aquí que él, como pastor experimentado, se ofrezca para realizar esa tarea, obviando el

81. Conf. 2,3,5. 
obstáculo que puede significar tanto la escasez de tiempo, como el estorbo de los curiosos que pueden descentrar la conversación o limitar la libertad de Volusiano.

Si ahora volvemos nuestra mirada al resto del corpus epistolar AgustínVolusiano, cabe preguntarse hasta qué punto Agustín conocía la situación particular de Volusiano y, en consecuencia, hasta qué punto estuvo acertado.

Si leemos la contestación de Volusiano e igualmente la carta de Marcelino que es una continuación real de la otra, difícilmente se puede evitar la impresión de que Agustín no ha dado en el clavo. La primera impresión es que Agustín está desinformado, que se imagina un Volusiano distinto del que existe en realidad, que le moldea "a su imagen y semejanza". Agustín parece que no ha intuido los problemas concretos de Volusiano, sino que se limita a darle un consejo, válido sin duda, pero sin relación inmediata con la problemática vivida por el destinatario.

En efecto, la Escritura que él defiende y valora, porque la recomienda, no aparece entre los temas de discusión de aquel círculo de intelectuales a que hace referencia Volusiano en su carta. Y sin embargo Agustín centra su primera carta en la recomendación de la Escritura, y en la segunda volverá sobre ella. El grupo se muestra tentado por el escepticismo, que no es el problema que Agustín parece presuponer en Volusiano. El obispo se imagina problemas con la Escritura y luego resulta que se trata de dificultades de otro tipo.

Tal es ciertamente la primera impresión, pero hemos de insistir en lo de primera. A una reflexión posterior las conclusiones son ligeramente distintas. De entrada cabe establecer una distinción: entre Volusiano y sus socios intelectuales. Mientras la carta 132 va dirigida a Volusiano en persona, las otras tienen por destinatario intencional a todo el grupo de que él formaba parte. De los mismos textos se extrae la conclusión de que no se puede equiparar totalmente a Volusiano con el grupo de amigos. Marcelino aporta un dato elocuente al respecto: él afirma que en la ciudad abundan muchos sujetos que se esfuerzan en apartarle de la estabilidad de la verdadera fe ${ }^{82}$. Lo que puede interpretarse en el sentido de que Volusiano tenía ya prácticamente un pie dentro, siendo muy distinta la situación de los demás. Cabe pensar que en el grupo todos compartían dificultades idénticas pero la actitud interior era distinta; mientras unos las veían como un obstáculo que deseaban superar para pasar a la otra orilla, otros las veían como la confirmación de que la otra orilla era inaccesible. Volusiano sin duda estaba entre

82. Epist. 136,1. 
los primeros; él con gusto hubiese expuesto a Agustín todas sus dudas, de no habérselo impedido los cánones del género epistolar que recomendaban la brevedad.

Así, pues, establecida la diferencia entre Volusiano y el grupo, resulta menos extraña la diferencia entre el contenido de la primera carta y el de las otras. Agustín le creía cerca y por esa razón le invita a dar el último paso que es la lectura de la Escritura.

Pero incluso dejando de lado el aspecto indicado, tras una ulterior reflexión Agustín tampoco anda desencaminado. Por una parte, los contenidos de la fe cristiana no se pueden separar de la Escritura, su continente. Cualquier dificultad contra dicha fe se resuelve en última instancia en dificultad contra la Escritura. La objeción principal a la fe, la encarnación, es punto central de la Escritura. La objeción sobre la inconstancia de Dios es una objeción contra la Escritura en el difícil problema de siempre de la relación entre los dos Testamentos. El problema de los milagros tiene también su vertiente bíblica. Se trata de problemas filosóficos que implican a la Escritura en cuanto autoridad. Para Agustín, sin duda, la solución al problema filosófico se encuentra en la Escritura y en su recta interpretación.

Agustín no responde desde la Biblia, sino desde la filosofía, porque es obvio que aquella sólo tiene valor para quien la acepta previamente como "autoridad", y no era el caso de aquellos paganos. Pero no deja de apuntalar ante ellos dicha autoridad, aceptada la cual se acabarían sus dificultades.

P. DE LUIS

Estudio Teológico Agustiniano

Valladolid 